\section{Summary of the 2017 thyroid radiofrequency ablation guideline and comparison with the 2012 guideline}

\author{
Ji-hoon Kim¹, Jung Hwan Baek², Hyun Kyung Lim³ ${ }^{3}$ Dong Gyu Na, \\ 'Department of Radiology, Seoul National University Hospital, Seoul; Department of \\ Radiology and Research Institute of Radiology, Asan Medical Center, University of Ulsan \\ College of Medicine, Seoul; ${ }^{3}$ Department of Radiology, Soonchunhyang University Seoul \\ Hospital, Soonchunhyang University College of Medicine, Seoul; ${ }^{4}$ Department of Radiology, \\ GangNeung Asan Hospital, Gangneung; ${ }^{5}$ Department of Radiology, Human Medical Imaging \\ and Intervention Center, Seoul, Korea
}

Radiofrequency ablation (RFA) is a new, minimally invasive modality that serves as an alternative to surgery in patients with thyroid tumors. The Task Force Committee of the Korean Society of Thyroid Radiology developed recommendations for the optimal use of RFA for thyroid tumors in 2012 and revised them in 2017. Herein, we review and summarize the 2017 thyroid RFA guideline and compare it with the 2012 thyroid RFA guideline.

Keywords: Thyroid; Ultrasonography; Radiofrequency ablation; Ethanol ablation; Thyroid nodule; Thyroid neoplasms

\section{Introduction}

Ultrasound (US)-guided radiofrequency ablation (RFA) for thyroid lesions has been used to treat benign thyroid nodules and recurrent thyroid cancers [1,2]. The Korean Society of Thyroid Radiology (KSThR) proposed preliminary recommendations for RFA of benign thyroid nodules in 2009 [3] and published a second set of recommendations for thyroid RFA in 2012 [1]. The second set presented a comprehensive discussion of the indications for thyroid RFA, pre-procedural evaluations, procedures, post-procedural monitoring, efficacy, and safety based on evidence and expert opinions.

Since the 2012 thyroid RFA guideline, high-level published evidence in this field has been rapidly accumulating; thus, the KSThR started to revise the guideline in December 2015 and published the 2017 thyroid RFA guideline in 2018 [4].

This review summarizes the 2017 thyroid RFA guideline and discusses its major differences with the 2012 thyroid RFA guideline.

\section{Methodology}

In contrast with the 2012 guideline, the 2017 guideline used standard international tools to appraise

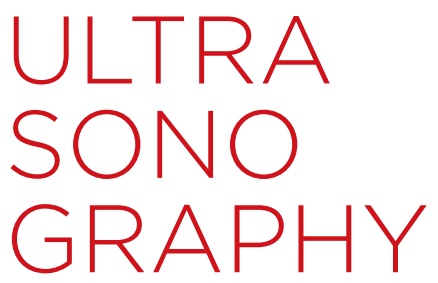

\section{REVIEW ARTICLE}

https://doi.org/10.14366/usg. 18044 pISSN: 2288-5919 e elSSN: 2288-5943 Ultrasonography 2019;38:125-134

Received: August 7, 2018

Revised: September 26, 2018

Accepted: September 27, 2018

Correspondence to: Jung Hwan Baek, MD, PhD, Department of Radiology and Research Institute of Radiology, Asan Medical Center, University of Ulsan College of Medicine, 88 Olympic-ro 43-gil, Songpa-gu, Seoul 05505, Korea

Tel. 82-2-3010-4352

Fax. 82-2-476-0090

E-mail: radbaek@naver.com

This is an Open Access article distributed under the terms of the Creative Commons Attribution NonCommercial License (http://creativecommons.org/ licenses/by-nc/4.0/) which permits unrestricted noncommercial use, distribution, and reproduction in any medium, provided the original work is properly cited.

Copyright @ 2019 Korean Society of Ultrasound in Medicine (KSUM)

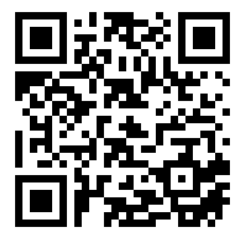

How to cite this article:

Kim JH, Baek JH, Lim HK, Na DG. Summary of the 2017 thyroid radiofrequency ablation guideline and comparison with the 2012 guideline. Ultrasonography. 2019 Apr;38(2):125-134. 
study quality, including the Cochrane risk of bias for randomized controlled trials (RCTs), the Risk of Bias Assessment tool for Nonrandomized Studies (RoBANS) for non-RCTs, the Quality Assessment of Diagnostic Accuracy Studies-2 (QUADAS-2) for diagnostic studies, and A Measurement Tool to Assess Systematic Reviews (AMSTAR) [5].

Tables 1 and 2 show the evidence level and the recommendation grading system established based on a review of the existing guidelines and other grading systems [6]. Study design and quality (risk of bias) were considered the main factors that determined the evidence level. For recommendation grading, the committee considered the quality of evidence, clinical benefits and harms, costs, patients' preferences, and value [5].

In the 2017 guideline, the modified Delphi method was used to establish consensus, especially for benefits and harms. The evidence level and net benefits were the main components underlying decisions concerning the recommendations [5]. The recommendation strength was discussed further, with a consideration of clinical applicability and impact on patient outcomes. Therefore, despite high Delphi scores, in some cases, the recommendation strength was downgraded according to the consensus of an expert committee. Finally, several considerations were described for the use of this guideline (i.e., harm and benefit, acceptability, applicability, and radiation dose). Table 3 illustrates the recommendations of the 2017 thyroid RFA guideline.

\section{Indications}

For benign thyroid nodules, the indications in the 2017 guideline are similar to those in the 2012 guideline. The 2017 guideline recommends thyroid RFA for patients with benign thyroid nodules complaining of symptomatic or cosmetic issues. In terms of nodule size or volume, no definite criteria for thyroid RFA have been established. The need for thyroid nodule treatment depends on the patient's symptoms or cosmetic problems, which vary according to the individual's neck circumference or thyroid nodule location [1]. Cosmetic problems are influenced by the nodule location (i.e., isthmus) or neck circumference. Nodules that exceed $2 \mathrm{~cm}$ in diameter and continue to grow during the follow-up period may be considered for thyroid RFA based on symptoms, cosmetic problems, and clinical concerns [7]. In addition, the 2017 guideline recommends thyroid RFA for toxic and pretoxic autonomously functioning thyroid nodules (AFTNs). No absolute contraindications

Table 1. Level of evidence

\begin{tabular}{lll}
\hline \multicolumn{1}{c}{ Evidence level } & \multicolumn{1}{c}{ Study design } & \multicolumn{1}{c}{ Internal validity (risk of bias assessment) } \\
\hline High & $\begin{array}{l}\text { RCT or SR/meta-analysis or non-randomized diagnostic study } \\
\text { (cohort or cross-sectional) }\end{array}$ & No concern \\
Moderate & $\begin{array}{l}\text { RCT or non-randomized diagnostic study (cohort or cross- } \\
\text { sectional) } \\
\text { Prospective cohort study }\end{array}$ & $\begin{array}{l}\text { Minor concerns with limitations in the major area of each } \\
\text { quality appraisal tool }\end{array}$ \\
& $\begin{array}{l}\text { Retrospective cohort study or non-randomized diagnostic study } \\
\text { (cohort or cross-sectional) or case-control study }\end{array}$ & $\begin{array}{l}\text { Severe concerns with limitations in the major area of each } \\
\text { quality appraisal tool }\end{array}$ \\
\hline
\end{tabular}

$\mathrm{RCT}$, randomized controlled trial; SR, systematic review.

Table 2. Grading of recommendations

\begin{tabular}{|c|c|c|c|}
\hline Grading & Definition & Evidence level & $\begin{array}{c}\text { Net benefit } \\
\text { (median, by Delphi score) }\end{array}$ \\
\hline Strong recommendation & $\begin{array}{l}\text { The benefit of the intervention is greater than the harm and the } \\
\text { evidence level is high. The intervention can be strongly recommended } \\
\text { in most contexts in clinical practice. }\end{array}$ & High or moderate & $\geq 7$ \\
\hline \multirow[t]{2}{*}{ Weak recommendation } & $\begin{array}{l}\text { The benefit and harm of the intervention may vary depending on the } \\
\text { clinical situation or patient/social value. }\end{array}$ & High or moderate & $4-6$ \\
\hline & $\begin{array}{l}\text { The intervention is recommended conditionally according to the } \\
\text { clinical circumstances. }\end{array}$ & Low & $\geq 7$ \\
\hline Against recommendation & $\begin{array}{l}\text { The harm of the intervention is greater than the benefit, and the } \\
\text { evidence level is high or moderate; thus, the intervention may not be } \\
\text { recommended in clinical practice. }\end{array}$ & High or moderate & $\leq 3$ \\
\hline Insufficient & $\begin{array}{l}\text { It is not possible to determine the recommendation grade because of } \\
\text { the lack of evidence or a low level of evidence; thus, further evidence } \\
\text { is needed. }\end{array}$ & Low & $\leq 6$ \\
\hline
\end{tabular}


Table 3. Summary of recommendations

\begin{tabular}{|c|c|c|c|c|}
\hline Key question & Recommendation & $\begin{array}{l}\text { Evidence } \\
\text { level }\end{array}$ & $\begin{array}{c}\text { Delphi } \\
\text { score }\end{array}$ & $\begin{array}{l}\text { Grading of } \\
\text { recommendation }\end{array}$ \\
\hline \multirow[t]{5}{*}{$\begin{array}{l}\text { 1. What are the indications for RFA for benign } \\
\text { thyroid nodules? }\end{array}$} & $\begin{array}{l}\text { 1-1. RFA is indicated for patients with benign thyroid nodules } \\
\text { complaining of symptomatic or cosmetic problems. }\end{array}$ & Moderate & 9 & Strong \\
\hline & $\begin{array}{l}\text { 1-2. Thyroid nodules should be confirmed as benign on at } \\
\text { least two US-guided FNA or CNB before RFA. }\end{array}$ & Moderate & 8 & Strong \\
\hline & $\begin{array}{l}\text { 1-3. A single benign diagnosis on FNA or CNB is sufficient } \\
\text { when the nodule has US features highly specific for benignity } \\
\text { (isoechoic spongiform nodule or partially cystic nodules with } \\
\text { intracystic comet tail artifact). }\end{array}$ & High & 8 & Strong \\
\hline & $\begin{array}{l}\text { 1-4. A single benign diagnosis on FNA or CNB is sufficient for } \\
\text { confirmation of a benign nodule identified as an AFTN. }\end{array}$ & Low & 8 & Weak \\
\hline & 1-5. RFA can be indicated for AFTN, either toxic or pre-toxic. & Moderate & 8 & Weak \\
\hline $\begin{array}{l}\text { 2. What are the indications for RFA for recurrent } \\
\text { thyroid cancers? }\end{array}$ & $\begin{array}{l}\text { 2. RFA can be performed for curative or palliative purposes } \\
\text { in recurrent thyroid cancers at the thyroidectomy bed and } \\
\text { cervical lymph nodes for patients at high surgical risk or who } \\
\text { refuse surgery. }\end{array}$ & Moderate & 9 & Strong \\
\hline $\begin{array}{l}\text { 5. What is the appropriate laboratory } \\
\text { and imaging evaluation for patients with } \\
\text { symptomatic benign thyroid nodule or } \\
\text { recurrent thyroid cancer before RFA? }\end{array}$ & $\begin{array}{l}\text { 3. Before RFA of a symptomatic benign thyroid nodule or } \\
\text { recurrent thyroid cancer, a pre-procedural checklist should be } \\
\text { evaluated (Table 4). }\end{array}$ & Moderate & 8 & Weak \\
\hline $\begin{array}{l}\text { 6. What is the appropriate recommendation for } \\
\text { patients taking anticoagulants or anti-platelet } \\
\text { drugs before RFA? }\end{array}$ & $\begin{array}{l}\text { 4. Before RFA, patients with a bleeding tendency, such as } \\
\text { those taking anticoagulation medications or those with } \\
\text { disorders affecting the coagulation cascade, should be } \\
\text { thoroughly evaluated, and any problems should be corrected. }\end{array}$ & Low & 10 & Weak \\
\hline \multirow[t]{2}{*}{$\begin{array}{l}\text { 7. What is the appropriate technique for RFA of } \\
\text { benign thyroid nodules? }\end{array}$} & $\begin{array}{l}\text { 5-1. For pain control of RFA of benign thyroid nodules, } \\
\text { local anesthesia, rather than general anesthesia or deep } \\
\text { sedation, is recommended. Perithyroidal lidocaine injection is } \\
\text { recommended as the local anesthesia technique. }\end{array}$ & Moderate & 8 & Strong \\
\hline & $\begin{array}{l}\text { 5-2. For RFA of benign thyroid nodules, the trans-isthmic } \\
\text { approach method and moving-shot technique are } \\
\text { recommended as the standard procedure. }\end{array}$ & Moderate & 8.5 & Strong \\
\hline $\begin{array}{l}\text { 8. What is the appropriate technique for RFA of } \\
\text { recurrent thyroid cancers? }\end{array}$ & $\begin{array}{l}\text { 6. For RFA of recurrent thyroid cancers, perilesional lidocaine } \\
\text { injection, the hydrodissection technique, and the moving- } \\
\text { shot technique are recommended as standard techniques. }\end{array}$ & Low & 8 & Weak \\
\hline $\begin{array}{l}\text { 9. What is the appropriate clinical, laboratory, } \\
\text { and imaging evaluation for nonfunctioning } \\
\text { benign thyroid nodules after RFA? }\end{array}$ & $\begin{array}{l}\text { 7. After RFA for nonfunctioning benign thyroid nodules, } \\
\text { clinical, laboratory, and imaging checklists should be } \\
\text { evaluated (Table 7). }\end{array}$ & Moderate & 8 & Weak \\
\hline $\begin{array}{l}\text { 10. What is the appropriate clinical, laboratory, } \\
\text { and imaging evaluation for AFTN after RFA? }\end{array}$ & $\begin{array}{l}\text { 8. After RFA for AFTN, clinical, laboratory, and imaging } \\
\text { checklists should be evaluated (Table 7). }\end{array}$ & Moderate & 8 & Weak \\
\hline \multirow[t]{2}{*}{$\begin{array}{l}\text { 13. What is the appropriate composition of } \\
\text { benign thyroid nodules for RFA? }\end{array}$} & $\begin{array}{l}\text { 9-1. RFA is recommended as the first-line treatment method } \\
\text { for solid and predominantly solid nodules, although it is also } \\
\text { an effective treatment method to manage non-functioning } \\
\text { thyroid nodules, regardless of the degree of solidity. }\end{array}$ & Moderate & 8 & Strong \\
\hline & $\begin{array}{l}\text { 9-2. EA is recommended as the first-line treatment method } \\
\text { for cystic and predominantly cystic nodules. RFA can be } \\
\text { recommended as the next step in cases with incomplete } \\
\text { resolved symptoms or recurrence following EA. }\end{array}$ & High & 9 & Strong \\
\hline $\begin{array}{l}\text { 14. Is a single treatment enough for patients } \\
\text { with non-functioning thyroid nodules? }\end{array}$ & $\begin{array}{l}\text { 10. Depending on the size and location of the nodule, } \\
\text { additional treatment may be required. Additional treatment } \\
\text { may be considered if the nodule shows marginal regrowth } \\
\text { or if cosmetic or symptomatic problems are incompletely } \\
\text { resolved. }\end{array}$ & Moderate & 8 & Strong \\
\hline 18. Is RFA a safe and tolerable procedure? & $\begin{array}{l}\text { 11. RFA is safe and well-tolerated and is associated with a low } \\
\text { incidence of complications when performed by experienced } \\
\text { operators. }\end{array}$ & High & 9 & Strong \\
\hline
\end{tabular}

RFA, radiofrequency ablation; US, ultrasoound; FNA, fine-needle aspiration; CNB, core-needle biopsy; AFTN, autonomously functioning thyroid nodule; EA, ethanol ablation. 
for thyroid RFA are presented in the 2012 and 2017 guidelines. The 2012 guideline recommended careful ablation in patients with a cardiac pacemaker or in pregnant women; however, the 2017 guideline recommends the use of a thyroid-dedicated bipolar electrode for these patients. RFA is not suitable for thyroid nodules with heavy calcifications because nodule puncture and the movingshot technique are difficult in such nodules.

Regarding benign cytopathological results, the 2012 guideline suggested that at least two biopsy results should be obtained for all indicated nodules. The 2017 guideline also suggests that 2 benign biopsy results should be obtained; however, a single benign diagnosis on fine-needle aspiration (FNA) or core-needle biopsy (CNB) is sufficient when the nodule has US features that are highly specific for benignity (isoechoic spongiform nodule or partially cystic nodules with an intracystic comet tail artifact) or when the nodule is identified as an AFTN [1,4].

In recurrent thyroid cancers, both the 2017 and 2012 guidelines suggest RFA for patients at high surgical risk or for those who refuse surgery $[1,4]$. In addition, the 2017 guideline suggests two treatment strategies: curative and palliative. Curative RFA for recurrent cancer refers to the complete treatment of any recurrent tumors visible on US. In recent studies undertaken for curative purposes, the number of locally recurrent tumors was $<3$ or 4 per patient and the greatest tumor diameter was $<1.5-2 \mathrm{~cm}[8-10]$. Recurrent thyroid cancer can induce various symptoms, such as dysphagia, hoarseness, dyspnea, or cosmetic issues. Palliative RFA can be applied when it is judged that size reduction by RFA can reduce symptoms and improve the quality of life of a patient, even if radiologically complete removal is not possible [11].

For primary thyroid cancer, surgery is the standard treatment. Therefore, the 2012 guideline did not recommend RFA for primary cancers. The 2017 guideline recommends considering RFA in selected patients (i.e., in patients who refuse surgery or who cannot undergo an operation) $[1,4]$. However, the optimal candidates and clinical outcomes of RFA have not been established for primary thyroid cancer. Therefore, RFA remains an experimental tool that requires further investigation. Several reports have suggested that RFA or laser ablation (LA) may not be effective for rapidly growing primary thyroid cancers, such as anaplastic cancer [12-15].

For follicular neoplasms, the 2012 guideline did not recommend RFA because of the lack of evidence of treatment benefit for RFA. However, a recent 5-year follow-up study revealed that RFA can be an effective and safe method to treat patients with follicular neoplasms $<2 \mathrm{~cm}$ in size [16]. In another study, two out of six lesions that were graded as Bethesda- 3 or Bethesda- 4 and measured $>2 \mathrm{~cm}$ in size regrew after RFA and were finally diagnosed as minimally invasive follicular cancer and follicular neoplasm of indeterminate malignant behavior, respectively [17]. Therefore, the application of RFA for follicular neoplasms remains debatable [1,4].

\section{Pre-procedural Evaluations}

Table 4 presents the checklist before RFA. The checklist of the 2012 guideline is similar to that of the 2017 guideline [1,4]; however, the 2017 guideline includes a detailed description of the pathological diagnosis and laboratory tests. A US examination is considered important to establish the treatment plan by characterizing benign nodules or recurrent cancers and by evaluating the surrounding critical anatomical structures. Three orthogonal diameters, including the largest diameter, should be measured by US, and nodule or tumor volume can be calculated using the equation $V=\pi a b c / 6$, where $V$ is the volume, $a$ is the maximum diameter, and $b$ and $c$ are the other two perpendicular diameters $[2,18]$. When the serum concentration of thyrotropin (TSH) is reduced, physicians should document whether a patient is being treated with thyroid hormones or has hyperthyroidism. If hyperthyroidism is clinically suggested, a technetium ${ }^{99 \mathrm{~m}} \mathrm{Tc}$ pertechnetate scan or a ${ }^{123}$ I thyroid scan may be helpful to identify AFTNs $[19,20]$. Computed tomography (CT) or magnetic resonance imaging examinations may also be helpful to evaluate the intrathoracic extent of benign thyroid nodules $[1,4]$. Prior to RFA of recurrent thyroid cancer (Table 4), tumor recurrence should be confirmed by US-guided FNA with a washout thyroglobulin $(\mathrm{Tg})$ level measurement. Neck CT is recommended to detect additional recurrent tumors that are not detected on US, and it may also be useful for the post-RFA evaluation of recurrent tumors $[1,4]$.

Both the 2012 and 2017 guidelines have similar recommendations for the management of patients with a bleeding tendency and the content of informed consent $[1,4]$. Patients who take drugs for a bleeding tendency should be informed of the need to discontinue those drugs before RFA (Table 5): 7-10 days before for aspirin or clopidogrel, 3-5 days for warfarin, and 4-6 hours for heparin. Patients can resume taking heparin 2-6 hours after RFA, warfarin the night following RFA, and aspirin (or clopidogrel) the next day [21]. However, the recommendations for the discontinuation of antiplatelet therapy with platelet aggregation inhibitors vary according to clinical judgment based on the patient's condition, the planned procedure, risk factors, desires, and the cardiologist's opinion. Physicians should compare the benefits of RFA with the potential complications related to the interruption of these drugs. If required, they should consider changing warfarin to heparin, which has a shorter half-life (1-2 hours) [21]. Informed consent should include the items listed in Table $6[1,4]$. 
Table 4. Pre-procedural checklist before RFA

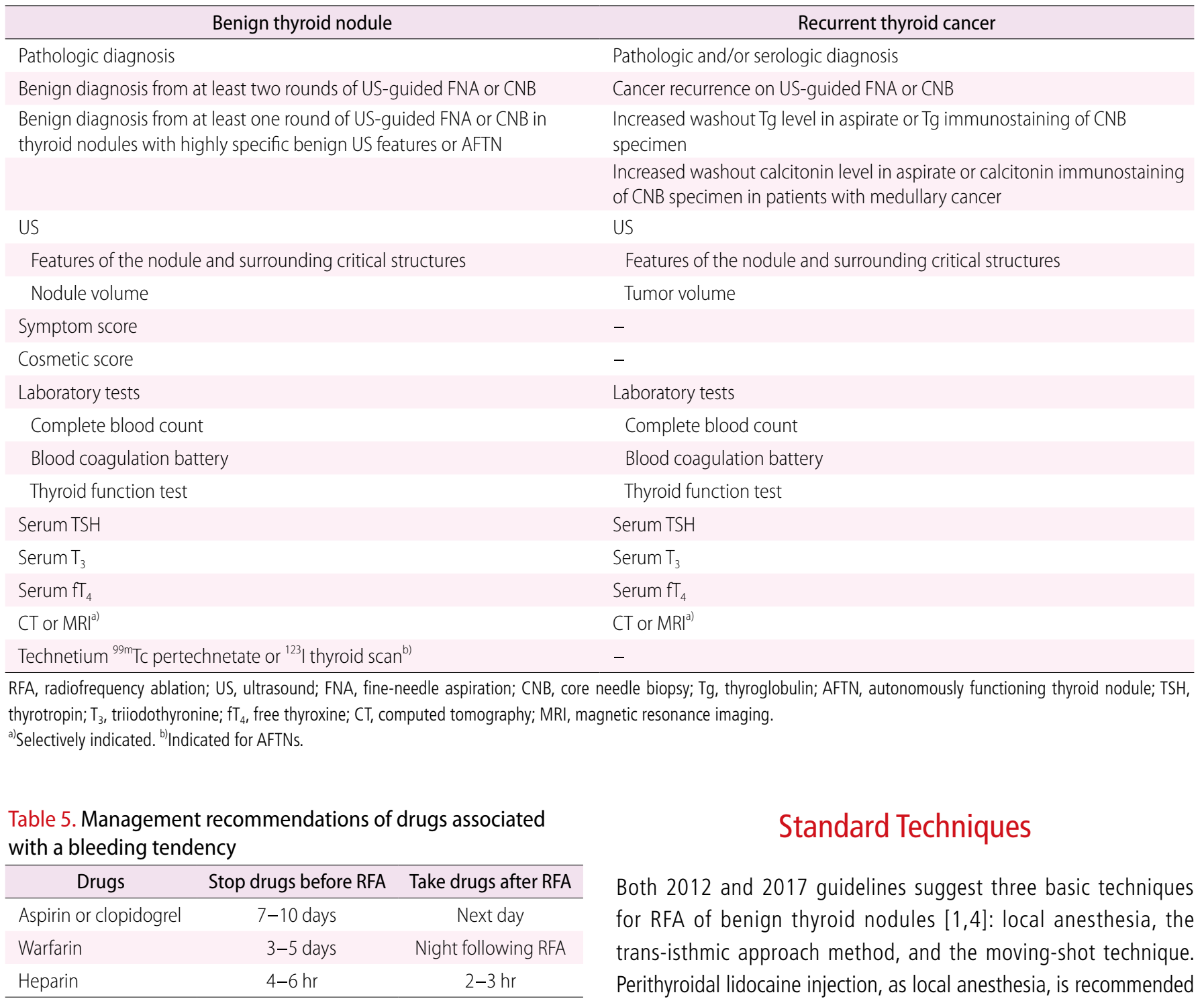

RFA, radiofrequency ablation; US, ultrasound; FNA, fine-needle aspiration; CNB, core needle biopsy; Tg, thyroglobulin; AFTN, autonomously functioning thyroid nodule; TSH, thyrotropin; $\mathrm{T}_{3}$, triiodothyronine; $\mathrm{fT}_{4}$, free thyroxine; $\mathrm{CT}$, computed tomography; $\mathrm{MRI}$, magnetic resonance imaging.

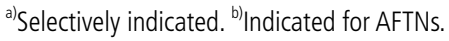

Table 5. Management recommendations of drugs associated with a bleeding tendency

\begin{tabular}{|c|c|c|}
\hline \multicolumn{3}{|c|}{ Benign thyroid nodule } \\
\hline \multicolumn{3}{|l|}{ Pathologic diagnosis } \\
\hline \multicolumn{3}{|c|}{ Benign diagnosis from at least two rounds of US-guided FNA or CNB } \\
\hline \multicolumn{3}{|c|}{$\begin{array}{l}\text { Benign diagnosis from at least one round of US-guided FNA or CNB in } \\
\text { thyroid nodules with highly specific benign US features or AFTN }\end{array}$} \\
\hline \multicolumn{3}{|l|}{ US } \\
\hline \multicolumn{3}{|c|}{ Features of the nodule and surrounding critical structures } \\
\hline \multicolumn{3}{|l|}{ Nodule volume } \\
\hline \multicolumn{3}{|l|}{ Symptom score } \\
\hline \multicolumn{3}{|l|}{ Cosmetic score } \\
\hline \multicolumn{3}{|l|}{ Laboratory tests } \\
\hline \multicolumn{3}{|c|}{ Complete blood count } \\
\hline \multicolumn{3}{|c|}{ Blood coagulation battery } \\
\hline \multicolumn{3}{|c|}{ Thyroid function test } \\
\hline \multicolumn{3}{|l|}{ Serum TSH } \\
\hline \multicolumn{3}{|l|}{ Serum $T_{3}$} \\
\hline \multicolumn{3}{|l|}{ Serum $\mathrm{fT}_{4}$} \\
\hline \multicolumn{3}{|l|}{ (T or $\left.M R\right|^{a)}$} \\
\hline \multicolumn{3}{|c|}{ Technetium ${ }^{99 m}$ Tc pertechnetate or ${ }^{123}$ I thyroid scan ${ }^{\text {b) }}$} \\
\hline \multicolumn{3}{|c|}{ 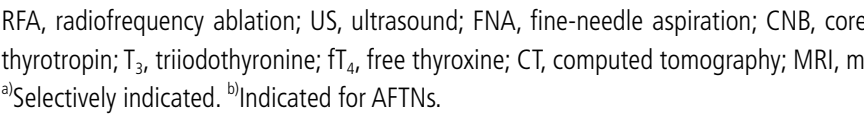 } \\
\hline \multicolumn{3}{|c|}{$\begin{array}{l}\text { Table } 5 \text {. Management recommendations of drugs associated } \\
\text { with a bleeding tendency }\end{array}$} \\
\hline Drugs & Stop drugs before RFA & Take drugs after RFA \\
\hline Aspirin or clopidogrel & $7-10$ days & Next day \\
\hline Warfarin & $3-5$ days & Night following RFA \\
\hline Heparin & $4-6 \mathrm{hr}$ & $2-3 \mathrm{hr}$ \\
\hline
\end{tabular}

RFA, radiofrequency ablation.

\section{Table 6. Checklist for informed consent}

\footnotetext{
1. Ablated thyroid nodules decrease gradually in size over several months to years.

2. Number of expected treatment sessions

3. Possibility of regrowth of the treated nodule and the need for additional treatment

4. Possibility of experiencing various degrees of pain during the ablation

5. Complications of RFA

6. Patients should inform the physician about their history of thyroid surgery, the side effects of any drugs they are taking, and whether they are taking drugs such as antiplatelet drugs, anticoagulants, or thyroid hormones.

7. Further observation or admission may be required after RFA, depending on the patient's condition after ablation.
}

RFA, radiofrequency ablation.

\section{Standard Techniques}

Both 2012 and 2017 guidelines suggest three basic techniques for RFA of benign thyroid nodules $[1,4]$ : local anesthesia, the trans-isthmic approach method, and the moving-shot technique. Perithyroidal lidocaine injection, as local anesthesia, is recommended to control pain during ablation, rather than using general anesthesia or sedation. Sensory nerves are usually present at the thyroid capsule, but not inside the thyroid gland. General anesthesia or sedation may delay the detection of complications and can cause serious complications during ablation [22].

The 2017 guideline recommends advanced techniques (vascular ablation techniques) to minimize marginal regrowth [23]. Two different vascular ablation techniques are available: artery-first ablation and marginal venous ablation. The artery-first ablation technique can be used for hypervascular nodules with a prominent feeding artery. However, the marginal venous ablation technique is useful for most thyroid nodules because thyroid nodules usually have marginal draining veins.

The technique of RFA for AFTNs, primary cancers, and follicular neoplasms is similar to that for benign thyroid nodules; however, a 
safety margin is also necessary for the complete eradication of an AFTN, primary cancer, or follicular neoplasm [23].

For treating recurrent thyroid cancers, the 2017 guideline recommends peritumoral lidocaine injection, the hydrodissection technique, and the moving-shot technique. The moving-shot technique has been suggested to be suitable for treating recurrent thyroid cancers, including the soft tissue surrounding the recurrent tumors [9]. Recurrent thyroid cancers may abut the normal neck structures, such as the recurrent laryngeal nerve, esophagus, or trachea. Before ablation, careful evaluation of the tumor and its surrounding structures are important [24]. Moreover, in addition to peritumoral lidocaine injection, the hydrodissection technique is useful for separating the tumor from critical structures [23,24]. A solution of $5 \%$ dextrose is preferred to normal saline as the injection material because normal saline is anionic and can therefore conduct electricity [25]. An electrode with a small active tip (i.e., 0.38 or 0.5 $\mathrm{cm}$ ) is effective and safe for treating small primary and/or recurrent tumors or those that are close to critical structures [23].

\section{Post-procedural Evaluations}

Both the 2012 and 2017 guidelines recommend a similar postprocedural checklist (Table 7) to evaluate the effectiveness of RFA [1,4]; however, the 2017 guideline describes the role of each examination in detail. Moreover, the 2017 guideline suggests indications for additional ablation of benign and malignant thyroid lesions. In benign thyroid nodules, additional ablation is indicated if a viable portion with nodule vascularity is detected on gray-scale and color Doppler US in addition to persistent symptomatic and cosmetic problems [2,19]; this is because the under-ablated nodule portion with vascularity has considerable potential for regrowth on follow-up. However, color Doppler US is not sufficiently sensitive to detect small vessels and slow blood flow $[18,26]$. To overcome these disadvantages of color Doppler US, some authors have suggested contrast-enhanced US as an ancillary diagnostic tool for detecting the under-ablated portion after the RFA procedure [27].

The 2017 guideline includes detailed recommendations following RFA of AFTNs. For instance, it states that thyroid function should be monitored by measuring $\mathrm{TSH}_{1} \mathrm{~T}_{3}$, and free $\mathrm{T}_{4}$ levels at each follow-up $[19,20,28]$. Based on TSH changes, anti-thyroid medications can be reduced or stopped. The measurement of auto-antibody (anti-thyroid peroxidase antibody and anti-Tg antibody) levels is also necessary in some cases. After RFA, patients with elevated auto-antibody levels may develop subclinical hypothyroidism [29]. Therefore, if thyroid antibody levels are elevated before ablation, careful evaluation of thyroid function is necessary during the follow-up period. Following RFA of AFTNs, US examination should be performed at each followup. On each US examination, changes in size, volume, intranodular vascularity, and echogenicity are evaluated. If thyroid function or symptoms are incompletely resolved, repeated RFA or another treatment, such as medication, are required. The decision to perform repeated RFA may be made based on the serum TSH level rather than on a scan or on the under-ablated portion on US. Rarely, because complete ablation of hot nodules can cause hypothyroidism,

\section{Table 7. Post-procedural checklist after RFA}

\begin{tabular}{|c|c|}
\hline Benign thyroid nodule & Recurrent thyroid cancer \\
\hline US & US \\
\hline $\begin{array}{l}\text { Features of ablated zone to detect the under-ablated portion with } \\
\text { vascularity on color Doppler US }\end{array}$ & $\begin{array}{l}\text { Features of ablated zone to detect the under-ablated portion with } \\
\text { vascularity on color Doppler US }\end{array}$ \\
\hline Nodule volume & Tumor volume \\
\hline Symptom score & - \\
\hline Cosmetic score & - \\
\hline Laboratory tests & Laboratory tests \\
\hline Thyroid function test ${ }^{\text {a) }}$ & Thyroid function test \\
\hline Serum TSH & Serum TSH \\
\hline Serum $T_{3}$ & Serum $T_{3}$ \\
\hline \multirow[t]{2}{*}{ Serum $\mathrm{fT}_{4}$} & Serum $\mathrm{fT}_{4}$ \\
\hline & Serum Tg, anti-Tg antibody \\
\hline (T or MRI $\left.\right|^{\mathrm{a}}$ & CT or $M R l^{a)}$ \\
\hline Technetium ${ }^{99 m} \mathrm{TC}$ pertechnetate or a ${ }^{123}$ I thyroid scan $^{\text {b) }}$ & - \\
\hline
\end{tabular}

RFA, radiofrequency ablation; US, ultrasound; $\mathrm{TSH}$, thyrotropin; $\mathrm{T}_{3}$, triiodothyronine; $\mathrm{fT}_{4}$, free thyroxine; $\mathrm{Tg}$, thyroglobulin; $\mathrm{CT}$, computed tomography; MRI, magnetic resonance imaging.

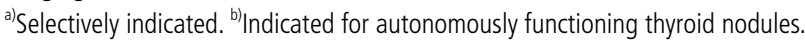


the decision to perform additional ablation should be carefully made according to changes in the serum TSH level. Repeat RFA may be performed during the follow-up period if the serum TSH level is not normalized after the first RFA.

After ablation of cervical recurrent tumors, tumor volume, maximum diameter, vascularity, and the development of new metastatic tumors should be evaluated during the follow-up period. In addition, serum $\mathrm{Tg}$ and anti-Tg antibody levels should be assessed after ablation $[30,31]$. Contrast-enhanced CT, especially in the early arterial phase with thin sections $(<2.5 \mathrm{~mm})$, may be useful to evaluate the presence of a viable remnant tumor or newly developed tumors [9]. Additional ablation may be planned if the follow-up US or CT demonstrates the presence of Doppler signals or an enhancing portion of the treated tumor. Several studies have suggested that the ablation zone can be more clearly visualized with contrast-enhanced US than with color Doppler US $[32,33]$.

There is a paucity of data regarding the application of RFA for primary thyroid cancer, and the post-procedural follow-up strategies are controversial, according to previous reports [34,35]. US is primarily recommended for the follow-up evaluation of the ablation zone. In addition, careful evaluation is necessary to detect the metachronous development of papillary thyroid cancer in other portions of the thyroid gland and newly occurring lymph node metastasis. Furthermore, CT seems to play an important complementary role in the detection of newly occurring lymph node metastasis. As shown in previous studies, reduced residual lesions after RFA indicate pathologically degenerative changes, and CNB or FNA is only recommended for lesions that increase in size or remain unchanged $[34,35]$.

\section{Clinical Outcomes}

Both the 2012 and 2017 guidelines state that RFA improves symptomatic and cosmetic issues caused by thyroid nodules $[1,4]$. In the 2017 guideline, RFA efficacy according to the solid component of the nodule is described based on evidence and is compared with the efficacy of ethanol ablation (EA) and LA.

The 2017 guideline describes the results of a systematic review. After RFA, the mean symptomatic and cosmetic scores improve. At the last follow-up, the mean volume reduction rate (VRR) is approximately $80 \%$. RFA achieves a greater VRR in cystic nodules than in solid nodules. In cystic and predominantly cystic thyroid nodules, EA is proposed as the first-line treatment. However, $18.7 \%-33 \%$ of cases experienced recurrence following EA for predominantly cystic thyroid nodules at a 1-month follow-up [3638]. In cases with incompletely resolved symptoms following EA, the mean VRR of EA-RFA combination therapy was $92 \%$ at 6 months [37]. Therefore, the 2017 guideline recommends EA-RFA combination therapy for incompletely resolved symptoms after initial EA [39].

Systematic reviews and meta-analyses have demonstrated that RFA and LA achieve significant volume reductions in benign solid thyroid nodules without any procedure-related deaths [40]. However, RFA shows superior efficacy to LA for volume reduction despite the smaller number of treatment sessions. Therefore, RFA may be the first-line treatment for solid thyroid nodules [40].

The 2017 guideline suggests that marginal regrowth poses an issue. Although the short-term RFA outcomes have mostly been reported to be safe and effective [41], longer follow-up studies have reported marginal regrowth. Marginal regrowth induces the recurrence of treated nodules [42]. At 4-year follow-up, larger nodules $(>20 \mathrm{~mL}$ ) required more treatment sessions than smaller nodules to achieve a similar VRR [43]. A previous randomized trial and Bayesian network meta-analysis revealed that two sessions of RFA were more effective than a single-session treatment, especially for nodules with a volume $>20 \mathrm{~mL}$ [26]. The results of these studies demonstrate that RFA cannot maintain long-term effects after a single treatment, especially when the index nodule volume is large.

The 2017 guideline states that RFA is effective in improving thyrotoxic symptoms, hormone levels, and scintigraphic findings in the management of AFTNs. In previous studies, single-session RFA allowed withdrawal of anti-thyroid medication in $21.7 \%-50 \%$ of patients. In one study, the methimazole dose was reduced after RFA in $78.3 \%$ of the patients [4].

The wide range of therapeutic effects may be caused by the amount of untreated tissue at the thyroid nodule margin, which can be the cause of insufficient volume reduction and explains the persistence of a hyperthyroid state $[19,28,44]$. Therefore, the complete treatment of AFTNs is important. The combination of RFA and radioactive iodine therapy should be investigated in the future.

The 2017 guideline suggests two types of RFA strategies for locally recurrent thyroid cancer $[8-11,30]$ : curative and palliative. A meta-analysis [31] reported that the pooled proportion of complete disappearance was $68.8 \%$ and that of recurrence at the treatment site was $0 \%$ after RFA. In addition, the pooled proportion of serum $\mathrm{Tg}$ level reduction was $71.6 \%$, and the tumor VRR was $50.9 \%-98.4 \%$. RFA can be applied for symptom relief even when radiologically complete removal is not possible. In their short-term follow-up study of 16 recurrent tumors, Park et al. [11] reported that $63.6 \%$ of patients experienced symptom relief after 6 months. However, in $62.5 \%$ of the patients, ablation was technically incomplete or failed due to intolerable pain, severe calcification, or tumor encasement of the major vessels [11]. Therefore, patients' symptoms and clinical conditions should be considered in palliative 
treatment. In a comparison between RFA and EA, RFA achieved a higher complete disappearance rate (68.8\% vs. $53.4 \%$, respectively; $\mathrm{P}=0.338)$ and a lower recurrence rate $(0.0 \%$ vs. $1.6 \% ; \mathrm{P}=0.996)$. However, these differences were not statistically significant. RFA (mean number of sessions: $\leq 1.3$ in $83.3 \%$ of studies) required fewer treatment session than EA (mean number of sessions: $\geq 2$ in $75 \%$ of studies) [31].

In cases of well-differentiated, low-risk primary cancers, the 2017 guideline suggests that RFA is effective in the management of primary thyroid cancer itself, albeit with a limitation in the control of regional microscopic metastasis or tiny multifocal cancers. Despite these limitations, a long-term follow-up study (mean duration, 48 months) of six patients reported a mean VRR of $98.5 \% \pm 3.3 \%$ and complete cancer disappearance on US in four patients [34]. No local tumor recurrence or metastatic lesions were reported during the follow-up period in both short-term and long-term follow-up studies.

\section{Safety}

Both the 2012 and 2017 guidelines suggest that RFA is safe, welltolerated, and associated with a low incidence of complications $[1,4]$. In a meta-analysis, the overall complication rate for benign nodules was $2.11 \%$ (95\% confidence interval [Cl], $1.15 \%$ to $3.06 \%)$, and the major complication rate was $1.27 \%(95 \% \mathrm{Cl}, 0.81 \%$ to $1.73 \%)$. For recurrent thyroid cancers, the overall complication rate was higher, at $10.98 \%(95 \% \mathrm{Cl}, 4.82 \%$ to $17.15 \%)$ and the rate of major complications was $6.71 \%(95 \% \mathrm{Cl}, 3.05 \%$ to $10.36 \%)$ [45]. Various complications have been reported, including major complications such as nerve injuries (e.g., recurrent laryngeal nerve, cervical sympathetic ganglion, brachial plexus, and spinal accessory nerve), nodule rupture, and permanent hypothyroidism, and minor complications such as hematoma, vomiting, skin burn, transient thyrotoxicosis, lidocaine toxicity, hypertension, and pain. However, no life-threatening complications were reported, and the sequelae rate was $0.21 \%[29,45,46]$.

The 2017 guideline recommends the use of effective and safe new devices. The 2012 guideline did not recommend the use of monopolar electrodes for pregnant women or patients with electrical devices, such as a cardiac pacemaker [1]. The 2017 guideline recommends that a new device (i.e., a bipolar electrode) can be a safer option for these patients [4]. The 2017 guideline also recommends the use of a 19-gauge, 0.38 - or $0.5-\mathrm{cm}$ active tip to treat small recurrent cancers. Although RFA is a safe modality for treating thyroid cancers, knowledge of US-based neck anatomy is mandatory for the effective and safe application of RFA.

\section{Conclusion}

In this review article, we summarized the 2017 guideline and discussed the major differences between the 2012 and 2017 guidelines. The recommendations in the 2017 guideline can provide the best scientific evidence and a consensus expert opinion regarding the use of RFA of the thyroid in clinical practice. Therefore, this revised guideline will be helpful for physicians in clinical practice.

ORCID: Ji-hoon Kim: https://orcid.org/0000-0002-6349-6950; Jung Hwan Baek: https://orcid.org/0000-0003-0480-4754; Hyun Kyung Lim: https://orcid.org/00000003-2319-3135; Dong Gyu Na: https://orcid.org/0000-0001-6422-1652

\section{Conflict of Interest}

All authors have no conflict of interest, except Baek JH. Financial activities related to the present article: none to disclose. Financial activities not related to the present article: patent holder of unidirectional ablation electrode. Other relationships: consultant for two radiofrequency companies, STARmed and RF Medical, since 2017.

\section{References}

1. Na DG, Lee JH, Jung SL, Kim JH, Sung JY, Shin JH, et al. Radiofrequency ablation of benign thyroid nodules and recurrent thyroid cancers: consensus statement and recommendations. Korean J Radiol 2012;13:117-125.

2. Jeong WK, Baek JH, Rhim H, Kim YS, Kwak MS, Jeong HJ, et al. Radiofrequency ablation of benign thyroid nodules: safety and imaging follow-up in 236 patients. Eur Radiol 2008;18:1244-1250.

3. Baek JH, Na DG, Lee JH, Jung SL, Sung JY, Sim J, et al. Korean Society of Thyroid Radiology recommendations for radiofrequency ablation of thyroid nodules [Internet]. Seoul: Korean Society of Thyroid Radiology, 2009 [cited 2018 May 10]. Available from: http://thyroidimaging.kr/.

4. Kim JH, Baek JH, Lim HK, Ahn HS, Baek SM, Choi YJ, et al. 2017 Thyroid Radiofrequency Ablation Guideline: Korean Society of Thyroid Radiology. Korean J Radiol 2018;19:632-655.

5. Choi SJ, Jeong WK, Jo AJ, Choi JA, Kim MJ, Lee M, et al. Methodology for developing evidence-based clinical imaging guidelines: joint recommendations by Korean Society of Radiology and national evidence-based healthcare collaborating agency. Korean J Radiol 2017;18:208-216.

6. Haugen BR, Alexander EK, Bible KC, Doherty GM, Mandel SJ, Nikiforov YE, et al. 2015 American Thyroid Association management guidelines for adult patients with thyroid nodules and differentiated thyroid cancer: the American Thyroid Association Guidelines Task Force on Thyroid Nodules and Differentiated Thyroid Cancer. Thyroid 
2016;26:1-133.

7. Deandrea M, Sung JY, Limone P, Mormile A, Garino F, Ragazzoni $F$, et al. Efficacy and safety of radiofrequency ablation versus observation for nonfunctioning benign thyroid nodules: a randomized controlled international collaborative trial. Thyroid 2015;25:890-896.

8. Dupuy DE, Monchik JM, Decrea C, Pisharodi L. Radiofrequency ablation of regional recurrence from well-differentiated thyroid malignancy. Surgery 2001;130:971-977.

9. Lim HK, Baek JH, Lee JH, Kim WB, Kim TY, Shong YK, et al. Efficacy and safety of radiofrequency ablation for treating locoregional recurrence from papillary thyroid cancer. Eur Radiol 2015;25:163170.

10. Kim JH, Yoo WS, Park YJ, Park DJ, Yun TJ, Choi SH, et al. Efficacy and safety of radiofrequency ablation for treatment of locally recurrent thyroid cancers smaller than $2 \mathrm{~cm}$. Radiology 2015;276:909-918.

11. Park KW, Shin JH, Han BK, Ko EY, Chung JH. Inoperable symptomatic recurrent thyroid cancers: preliminary result of radiofrequency ablation. Ann Surg Oncol 2011;18:2564-2568.

12. Cakir B, Topaloglu O, Gul K, Agac T, Aydin C, Dirikoc A, et al. Ultrasound-guided percutaneous laser ablation treatment in inoperable aggressive course anaplastic thyroid carcinoma: the introduction of a novel alternative palliative therapy: second experience in the literature. J Endocrinol Invest 2007;30:624-625.

13. Miyabayashi C, Ooiwa A, Katakura M, Ando T, Hasumoto $Y$, Terao $Y$, et al. A successful treatment of percutaneous radio frequency ablation for advanced thyroid cancer. Gan To Kagaku Ryoho 2005;32:1875-1877.

14. Owen RP, Silver CE, Ravikumar TS, Brook A, Bello J, Breining D. Techniques for radiofrequency ablation of head and neck tumors. Arch Otolaryngol Head Neck Surg 2004;130:52-56.

15. Pacella CM, Bizzarri G, Spiezia S, Bianchini A, Guglielmi R, Crescenzi $A$, et al. Thyroid tissue: US-guided percutaneous laser thermal ablation. Radiology 2004;232:272-280.

16. Ha SM, Sung JY, Baek JH, Na DG, Kim JH, Yoo H, et al. Radiofrequency ablation of small follicular neoplasms: initial clinical outcomes. Int J Hyperthermia 2017;33:931-937.

17. Dobrinja C, Bernardi S, Fabris B, Eramo R, Makovac P, Bazzocchi $G$, et al. Surgical and pathological changes after radiofrequency ablation of thyroid nodules. Int J Endocrinol 2015;2015:576576.

18. Jung SL, Baek JH, Lee JH, Shong YK, Sung JY, Kim KS, et al. Efficacy and safety of radiofrequency ablation for benign thyroid nodules: a prospective multicenter study. Korean J Radiol 2018;19:167-174.

19. Baek JH, Moon WJ, Kim YS, Lee JH, Lee D. Radiofrequency ablation for the treatment of autonomously functioning thyroid nodules. World J Surg 2009;33:1971-1977.

20. Faggiano $A$, Ramundo $V$, Assanti AP, Fonderico F, Macchia PE, Misso $C$, et al. Thyroid nodules treated with percutaneous radiofrequency thermal ablation: a comparative study. J Clin Endocrinol Metab 2012;97:4439-4445.
21. Kwok A, Faigel DO. Management of anticoagulation before and after gastrointestinal endoscopy. Am J Gastroenterol 2009; 104:3085-3097.

22. Bernardi S, Lanzilotti V, Papa G, Panizzo N, Dobrinja C, Fabris B, et al. Full-thickness skin burn caused by radiofrequency ablation of a benign thyroid nodule. Thyroid 2016;26:183-184.

23. Park HS, Baek JH, Park AW, Chung SR, Choi YJ, Lee JH. Thyroid radiofrequency ablation: updates on innovative devices and techniques. Korean J Radiol 2017;18:615-623.

24. Ha EJ, Baek JH, Lee JH. Ultrasonography-based thyroidal and perithyroidal anatomy and its clinical significance. Korean J Radiol 2015;16:749-766.

25. Laeseke PF, Sampson LA, Brace CL, Winter TC 3rd, Fine JP, Lee FT Jr. Unintended thermal injuries from radiofrequency ablation: protection with $5 \%$ dextrose in water. AJR Am J Roentgenol 2006;186(5 Suppl):S249-S254.

26. Huh JY, Baek JH, Choi H, Kim JK, Lee JH. Symptomatic benign thyroid nodules: efficacy of additional radiofrequency ablation treatment session: prospective randomized study. Radiology 2012;263:909-916.

27. Tang X, Cui D, Chi J, Wang Z, Wang T, Zhai B, et al. Evaluation of the safety and efficacy of radiofrequency ablation for treating benign thyroid nodules. J Cancer 2017;8:754-760.

28. Sung JY, Baek JH, Jung SL, Kim JH, Kim KS, Lee D, et al. Radiofrequency ablation for autonomously functioning thyroid nodules: a multicenter study. Thyroid 2015;25:112-117.

29. Baek JH, Lee JH, Sung JY, Bae JI, Kim KT, Sim J, et al. Complications encountered in the treatment of benign thyroid nodules with USguided radiofrequency ablation: a multicenter study. Radiology 2012;262:335-342.

30. Lee SJ, Jung SL, Kim BS, Ahn KJ, Choi HS, Lim DJ, et al. Radiofrequency ablation to treat loco-regional recurrence of welldifferentiated thyroid carcinoma. Korean J Radiol 2014;15:817826.

31. Suh CH, Baek JH, Choi YJ, Lee JH. Efficacy and safety of radiofrequency and ethanol ablation for treating locally recurrent thyroid cancer: a systematic review and meta-analysis. Thyroid 2016;26:420-428.

32. Papini E, Bizzarri G, Bianchini A, Valle D, Misischi I, Guglielmi R, et al. Percutaneous ultrasound-guided laser ablation is effective for treating selected nodal metastases in papillary thyroid cancer. J Clin Endocrinol Metab 2013;98:E92-E97.

33. Zhou W, Zhang L, Zhan W, Jiang S, Zhu Y, Xu S. Percutaneous laser ablation for treatment of locally recurrent papillary thyroid carcinoma <15 mm. Clin Radiol 2016;71:1233-1239.

34. Kim JH, Baek JH, Sung JY, Min HS, Kim KW, Hah JH, et al. Radiofrequency ablation of low-risk small papillary thyroidcarcinoma: preliminary results for patients ineligible for surgery. Int J Hyperthermia 2017;33:212-219.

35. Zhang M, Luo Y, Zhang Y, Tang J. Efficacy and Safety of 
Ultrasound-guided radiofrequency ablation for treating low-risk papillary thyroid microcarcinoma: a prospective study. Thyroid 2016;26:1581-1587.

36. Jang SW, Baek JH, Kim JK, Sung JY, Choi H, Lim HK, et al. How to manage the patients with unsatisfactory results after ethanol ablation for thyroid nodules: role of radiofrequency ablation. Eur J Radiol 2012;81:905-910.

37. Lee JH, Kim YS, Lee D, Choi H, Yoo H, Baek JH. Radiofrequency ablation (RFA) of benign thyroid nodules in patients with incompletely resolved clinical problems after ethanol ablation (EA). World J Surg 2010;34:1488-1493.

38. Suh CH, Baek JH, Ha EJ, Choi YJ, Lee JH, Kim JK, et al. Ethanol ablation of predominantly cystic thyroid nodules: evaluation of recurrence rate and factors related to recurrence. Clin Radiol 2015;70:42-47.

39. Park HS, Baek JH, Choi YJ, Lee JH. Innovative techniques for imageguided ablation of benign thyroid nodules: combined ethanol and radiofrequency ablation. Korean J Radiol 2017;18:461-469.

40. Ha EJ, Baek JH, Kim KW, Pyo J, Lee JH, Baek SH, et al. Comparative efficacy of radiofrequency and laser ablation for the treatment of benign thyroid nodules: systematic review including traditional pooling and bayesian network meta-analysis. J Clin Endocrinol
Metab 2015;100:1903-1911.

41. Fuller CW, Nguyen SA, Lohia S, Gillespie MB. Radiofrequency ablation for treatment of benign thyroid nodules: systematic review. Laryngoscope 2014;124:346-353.

42. Baek JH. Factors related to the efficacy of radiofrequency ablation for benign thyroid nodules. Ultrasonography 2017;36:385-386.

43. Lim HK, Lee JH, Ha EJ, Sung JY, Kim JK, Baek JH. Radiofrequency ablation of benign non-functioning thyroid nodules: 4-year followup results for 111 patients. Eur Radiol 2013;23:1044-1049.

44. Spiezia S, Garberoglio R, Milone F, Ramundo V, Caiazzo C, Assanti $A P$, et al. Thyroid nodules and related symptoms are stably controlled two years after radiofrequency thermal ablation. Thyroid 2009;19:219-225.

45. Chung SR, Suh CH, Baek JH, Park HS, Choi YJ, Lee JH. Safety of radiofrequency ablation of benign thyroid nodules and recurrent thyroid cancers: a systematic review and meta-analysis. Int J Hyperthermia 2017;33:920-930.

46. Kim C, Lee JH, Choi YJ, Kim WB, Sung TY, Baek JH. Complications encountered in ultrasonography-guided radiofrequency ablation of benign thyroid nodules and recurrent thyroid cancers. Eur Radiol 2017;27:3128-3137. 